\title{
Measuring the Relationship between Obesity and Low Back Pain: A Review Article
}

\author{
Qais Gasibat ${ }^{1, *}$, Nordin Bin Simbak ${ }^{1}$, Saad EL Barasi ${ }^{2}$, Adel Almangoush ${ }^{3}$ \\ ${ }^{1}$ Sultan Zainal Abidin University Malaysia \\ ${ }^{2}$ Higher Institute of Medical Professions, Benghazi \\ ${ }^{3}$ Faculty of Medical Technology, Misurata \\ *Corresponding author: drqaiss9@gmail.com
}

\begin{abstract}
Low back pain (LBP) is a common and elusive disorder. It cannot be comfortably diagnosed through clinical procedures, and little is understood about its etiology. From a public health perspective, it would be important to know if lifestyle factors, such as body weight, play an important role in its genesis. However, a look at the literature reveals some misperceptions. There are several hypotheses relating to a link between obesity and LBP. Increased mechanical demands resulting from obesity have been suspected of causing LBP through excessive wear and tear, and it has been suggested that metabolic factors associated with obesity may be detrimental. Thus, some consider it possible, but not particularly strong contributing factor of LBP, whereas others do not think that it is a risk factor of LBP. It has also been postulated that obesity may be a marker or an organizer for some other factors that are considered the causes of LBP. This study aims to measure the relationship between body weight and low back pain (LBP).
\end{abstract}

Keywords: low back pain, obesity, associated, risk factor, evidence-based practice

Cite This Article: Qais Gasibat, Nordin Bin Simbak, Saad EL Barasi, and Adel Almangoush, "Measuring the Relationship between Obesity and Low Back Pain: A Review Article." American Journal of Medical Sciences and Medicine, vol. 5, no. 2 (2017): 35-39. doi: 10.12691/ajmsm-5-2-3.

\section{Introduction}

Before consideration of obesity, it has to be clearly defined. Obesity refers to the storage of excess calories as fat. This definition separates weight, which is a measure of total mass, from obesity, which is a measure of fat mass. Body Mass Index (BMI) is the most widely used measure, and it involves a simple weight for height calculation which classifies adult weight as follows [1].

Table 1. Adult weight calculation

\begin{tabular}{ll}
\hline Classification & BMI $\left(\mathrm{kg} / \mathrm{m}^{2}\right)$ \\
\hline Underweight & $<20$ \\
Healthy weight & $20-24.9$ \\
Overweight & $25-29.9$ \\
Obese & $30-39.9$ \\
Morbidly Obese & 40 or more \\
\hline
\end{tabular}

However, a critical weakness in this measure is that, it fails to differentiate lean muscle mass from fat mass [1]. In addition, Mirtz et al [2] noted that obesity is a problem of epidemic proportion. For instance, more than 20 percent of Scotland population are obese and, if this trend continues, then by 2020 this figure will rise to 33 percent [3]. The issues of overweight and obesity are important public health problems because they are associated with increased risks for hypertension, coronary heart disease,
Type 2 diabetes, stroke, gall bladder disease, certain cancers, osteoarthritis, and sleep apnoea [3]. Indirect costs of these co-morbidities are difficult to quantify, but conservative estimates are in the order of hundreds of millions of pounds per year. These associations are clear; the link with LBP is therefore less.

LBP is a considerable public health problem and a common diagnosis resulting in absenteeism and need for disabilities pensions. For these reasons, it has been addressed as a "20th century medical disaster" [4]. It is frequently cited as a significant economic burden and the cause of much personal hardship. Commonly quoted figures indicate direct health care costs to the community care services at more than $£ 1$ billion each year including: $£ 141 \mathrm{~m}$ each year for consultations, $£ 150.6 \mathrm{~m}$ for physiotherapy, and £512m for hospital care [5]. When other costs, such as the estimated 4.9 million working days lost to LBP annually in the UK are taken into consideration, the total cost of LBP to the UK is closer to $£ 5$ billion per annum [39]. A more recent study [6] suggests that the economic impact of LBP may in fact be higher than previously estimated cost, and gives an estimate of $£ 9090$ million loss in the UK in 1998 through loss of work time alone. These authors suggest that previous economic analysis has only considered loss of work time through absence, with no consideration of the impact of those who, although at work, are performing restricted duties and consequently become less productive. LBP is a common but an elusive disorder. Possibly because of its heterogeneous and multidimensional nature, 
little is understood about its aetiology $[7,8]$. LBP is accepted as having a multifactorial aetiology. The main predictors of LBP include physical stress, such as prolonged lifting, driving, forceful or repetitive movements involving the back, and psychosocial stress, such as high perceived workload, time pressure, low control, lack of social support at work, and personal characteristics such as psychological status and tobacco use [9]. Hence the physical characteristics of body weight and obesity are less clear [10].

Obesity is one of the several lifestyle factors that have been suspected of not merely relating to, but in fact causing LBP. There are several hypotheses relating to a link between obesity and LBP. It has been postulated that excessive body weight could have mechanical ill effects on the back caused by excessive weight bearing [11-17]. These increased mechanical demands from obesity have been suspected of causing LBP through excessive wear and tear $[18,19]$. It has also been suggested that metabolic disorders may be detrimental. In this regard, Buckwalter et al [20] postulated that obesity, combined with its co-morbidities of diabetes and hypertension, may alter the pathophysiology of diseases of the tendons and ligaments during the process of aging, thus potentially leading to LBP.

The conventional wisdom behind this assumed link is that, as overweight people are at risk of osteoarthritis in weight bearing joints such as the knees, hips and feet, this trend has been alleged to generalise and extrapolate also to the spinal joints [19]. This conventional wisdom has led to weight loss being recommended as a treatment for chronic LBP, but little evidence exists to support this recommendation. The justification for weight loss as a general health improvement tool is clear. However, it implores the question "does obesity in LBP blind practitioners to other possible causes of the symptoms?” [21]. Therefore, it can be seen that there is a general assumption that being overweight is related to having LBP. However, scientific evidence to support this is scanty and conflicting [2,22]. A positive association between high body weight and LBP has been noted in some studies $[13,37]$, but not others $[23,24]$. With such societal costs, it is therefore clear that from a public health perspective, it would be important to determine whether lifestyle factors such as body weight and obesity play an important part in LBP genesis, since the literature reveals some misperception.

Even a superficial review of the literature makes it clear that some consider obesity a possible but not particularly strong contributory factor of LBP [25], whereas others do not think it is a risk factor of LBP at all [26]. For this reason and against this background of poor clarity, we decided to review the literature more thoroughly in search of any evidence based recommendations or conclusions that could be made on this elusive relationship..

\section{Methodology}

This study targeted articles in English from the databases of Medline, google scholar and science direct. Key words used in the search were Low Back Pain, Back Pain, Obesity, Body Mass Index, and Overweight. The main selection criterion was that the paper appeared to focus on the relationship between obesity and low back pain, regardless of methodology. Altogether, 16 articles were identified from the databases, Inclusion and selection into these 16 articles were contingent upon the relationship between obesity and LBP, proving to be the focus of the research and not merely an incidental consideration.

\section{Results and Discussion}

In this section, results obtained from the review of the aforementioned 16 studies are presented and discussed. More specifically, the relationship between obesity and low back pain is determined in this section. A summary is shown in the following table.

Table 2. Summary of Literature Reviewed

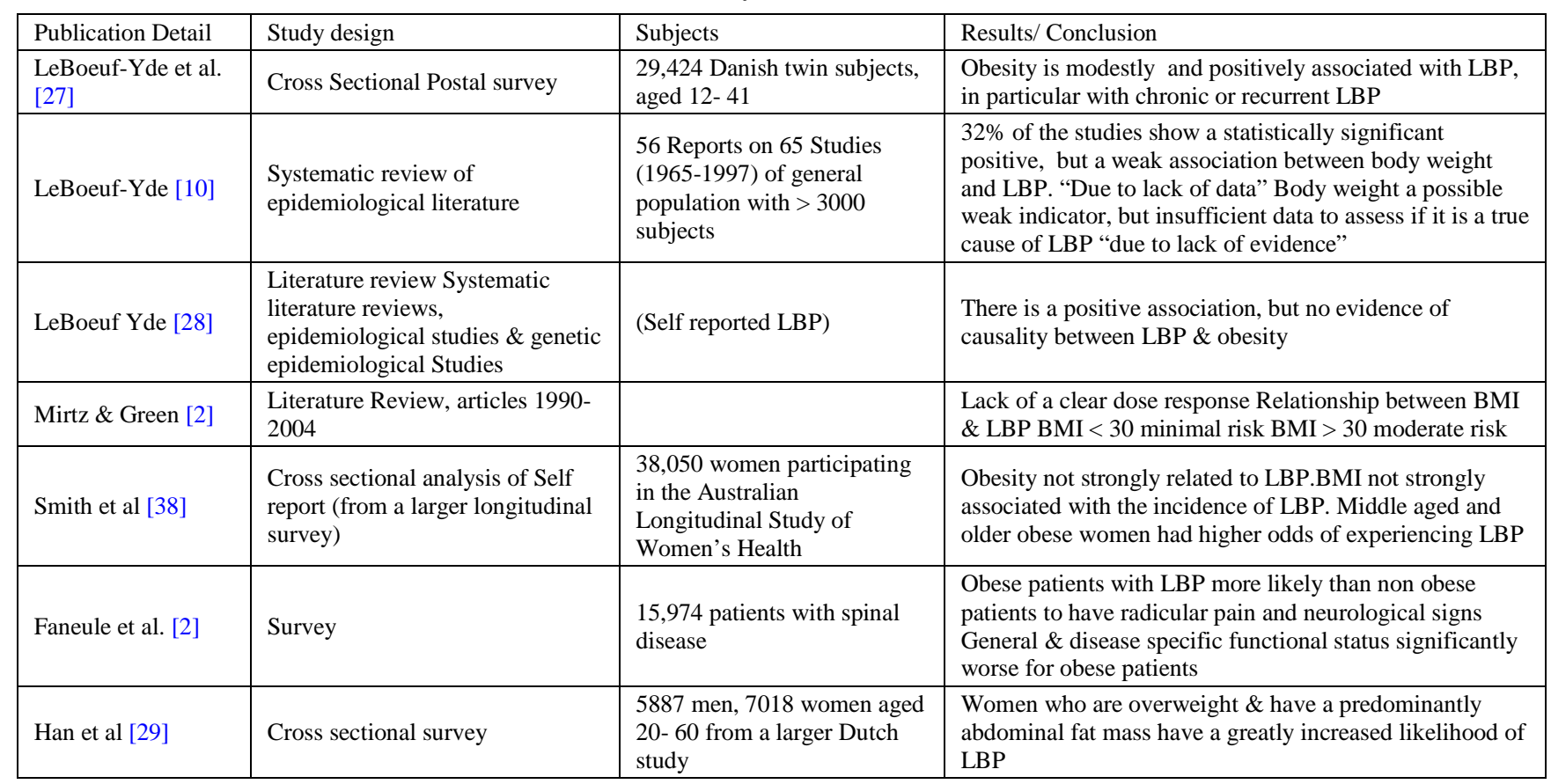




\begin{tabular}{|c|c|c|c|}
\hline Publication Detail & Study design & Subjects & Results/ Conclusion \\
\hline Webb et al [30] & $\begin{array}{l}\text { Multi-phase cross sectional } \\
\text { survey of musculoskeletal pain }\end{array}$ & $\begin{array}{l}\text { Sample of } 5752 \text { patients from } \\
3 \text { general practice registers in } \\
\text { the UK }\end{array}$ & $\begin{array}{l}\text { BMI is an important independent predictor of LBP and its } \\
\text { severity }\end{array}$ \\
\hline Mortimer et al. [25] & $\begin{array}{l}\text { Population based case referent } \\
\text { study? }\end{array}$ & $\begin{array}{l}2401 \text { subjects, } 791 \text { with LBP } \\
1610 \text { without LBP, taken } \\
\text { from a larger study in } \\
\text { Sweden }\end{array}$ & $\begin{array}{l}\text { High body weight is associated with an increased risk of } \\
\text { LBP in men but not women }\end{array}$ \\
\hline Baker \&Giles [31] & Prospective correlation study & $\begin{array}{l}71 \text { women, } 81 \text { men with } \\
\text { chronic LBP in a spinal pain } \\
\text { unit }\end{array}$ & $\begin{array}{l}\text { No support for the concept that patients with chronic LBP } \\
\text { are more overweight that the general population with the } \\
\text { possible exception of morbidly obese patients }\end{array}$ \\
\hline Tsuritami et al [32] & Survey & $\begin{array}{l}709 \text { Japanese women } \\
\text { aged }>40\end{array}$ & $\begin{array}{l}\text { No significant association between BMI and frequency of } \\
\text { LBP }\end{array}$ \\
\hline Baker \& Giles [31] & Prospective Correlational & 71women,81 men & $\begin{array}{l}\text { No support for concept that people with chronic pain are } \\
\text { more overweight that general population, with possible } \\
\text { exception of the morbidly obese }\end{array}$ \\
\hline Sjojie [33] & Cross sectional study & $\begin{array}{l}88 \text { urban Norwegian } \\
\text { adolescents }\end{array}$ & LBP associated with a higher than normal BMI \\
\hline Jones et al [34] & A matched case control study & $\begin{array}{l}\text { Adolescents } 28 \text { with LBP, } 28 \\
\text { without LBP }\end{array}$ & $\begin{array}{l}\text { BMI was not identified as a significant risk indicator for } \\
\text { recurrent non specific LBP }\end{array}$ \\
\hline
\end{tabular}

Pathogenesis of LBP was speculated by Leboeuf-Yde [10]. The author found that the increased mechanical loading caused by obesity might be responsible for low back pain through "excessive wear and tear. Baker and Giles [31] measured the Body Mass Index (BMI) of 152 persons with spinal pain. It was found that those with low back pain are not more overweight than the general population, since their average BMI (26.3) was identical. Consequently, it was concluded that with the exception of morbidly obese, excess weight is not a significant factor in the pathogenesis of low back pain. On the other hand, obesity in isolation could demonstrate no influence, but rather certain types of obesity may be present in people with a generally poor lifestyle, and that LBP occurs as a result of "the combination of several slovenly habits" in such a population [27].

A cross sectional study via a screening questionnaire of 5752 adults identified 4515 subjects with spinal pain. These were followed up via the Oswestry Disability Questionnaire. The authors found obesity to be a predictor of back pain and disability. The causal association was thought to be equivocal. However, it was also noted that the underweight BMI $(<20)$ group demonstrated a higher prevalence of all the categories of back pain than subjects with a normal BMI. The highest prevalence of LBP was found in obese $(>30)$ persons. The small number of participants involved limited the aforesaid study [30].

Han et al [29] reported that using BMI as a measure fails to differentiate lean muscle mass from overweight. The authors conducted a cross sectional study of 12,905 Dutch adults. They reported that a high waist/hip ratio, indicating a central obesity pattern, was significantly associated with chronic low back pain in women, but not in men. The authors did not provide evidence as to why this may be the case. The distribution of lean body mass and body fat was shown to be more closely associated with risk of chronic low back pain than Body Mass Index [29].

\section{Relationship between Obesity and Low Back Pain}

Regarding the relationship between obesity and LBP, the possible modifying effects of age, gender, type of work and smoking were measured by Leboeuf-Yde et al [27]. A cross sectional postal survey of 29,494 Danish twin subjects was conducted. The study identified a moderate, positive association between BMI and low back pain that increased with the duration of low back pain, particularly when chronic. This correlation also increased in direct proportion with recurrence of low back pain. The correlation was weak due to lack of a positive monotonic dose response. It was believed that the association was not causal, since the effect disappeared in the control group of 3,751 monozygotic twins with differing body size.

Fanuele et al [35] conducted a cross sectional study of 15,974 patients with spinal pain. Physical disability had been correlated with obesity $(\mathrm{p}<0.05)$. Compared with non-obese patients, the higher the BMI the greater the functional disability. Morbidly obese patients also had more radicular pain $(\mathrm{p}<0.001)$ (33.6\% non obese vs. $47.2 \%$ morbidly obese), and there were also greater neurological signs $(\mathrm{p}<0.01)(22.4 \%$ non obese vs. $32.7 \%$ morbidly obese). Obese patients tended to have more chronic pain (>3 months), and were statistically more likely to have comorbidities such as cardiovascular/pulmonary disease, cancer, degenerative and inflammatory arthritis, diabetes, stroke and endocrine disease. Although LBP may not be directly correlated with obesity, it was found that each might be related to anxiety, depression and psychological distress. The study established a high prevalence of depression amongst obese patients. The authors concluded that "without treatment of the obesity, increased BMI will likely impair the patient's functioning even after a successful spine treatment. In addition, a review of literature by Leboeuf-Yde [10] identified a weak 
association between obesity and low back pain, but there was not enough evidence to establish a causal relationship.

Mirtz \& Greene [2] conducted a further literature review, which found no clear evidence of a dose-response relationship between BMI and low back pain. The quality of the literature varied with a few samples of large enough size to be externally valid. However, it was thought that individuals with a BMI $<30$ are at minimal risk of developing low back pain. A moderate risk is found at BMI > 30, whilst $>40$ Body Mass Index indicates a high risk for future spinal pain.

Therefore, there is a general lack of clarity and conflicting results, which have led to the suggestion that obesity may be a marker [14] or a discoverer [11,13] for some other factors that cause LBP [10]. It has been postulated therefore, that obesity - in itself - has no influence on LBP, but certain types of obesity may be present in people with a generally poor lifestyle, and that it is "the combination of several slovenly habits that causes LBP” [27].

According to the biopsychosocial model, there is a relationship between biology, pathology, individual and environment, which results in the final expression of a disease or disorder in terms of pain or disability. This interplay may account for the lack of definitive evidence for or against a causal link between LBP and obesity [28]. Also, an inconsistency in the definition of what constitutes LBP and obesity has further clouded the issue.

\section{Advices for Patients}

Weight gain could be due to a reduction in exercise and increased consumption of energy-dense, high carbohydrate/fat, and low nutrient foodstuffs. Being overweight increases the risk of serious chronic diseases including Type II diabetes, cardiovascular disease, hypertension, stroke and some types of cancer [36]. The current evidence would not support to advise patients that reducing weight will produce a direct reduction in the intensity of their LBP [31]. This does not eliminate the benefit of weight loss on the comorbidities listed above. The authors suggest that clinicians who imply that weight loss may reduce back pain may cause distress to patients and reduce their adherence to any exercise regimen.

Obese individuals often have restricted exercise capacity, and so attempting to lose weight by exercising alone might be more difficult and stressful, and further disadvantaging the patient. The patients are advised to maintain and gradually improve fitness levels to avoid further weight gain. This is best facilitated by means of a sensible eating pattern and suitable programme of low impact regular exercise. In a perfect world, this would be moderate or vigorous exercise for 30 minutes, five times per week [31,36].

\section{Conclusion}

Although some of the studies identified a weak correlation, there was insufficient evidence to establish a direct causal relationship between obesity and LBP. A link could reasonably be expected between these two factors, since these conditions share many similarities; including lower occupational status, sedentary lifestyle and psychological distress. A mild positive relationship between weight and recurrent or chronic low back pain; although a direct causal link was not found. This signifies that perhaps obesity contributes to some important factors concealed within the heterogeneous nature of low back pain. Although LBP may not be directly correlated with obesity, it was found that each might be related to anxiety, depression, and psychological distress. Obesity is viewed as an important factor in the pathogenesis of LBP. On the other hand, obesity in isolation could demonstrate no influence, but rather certain types of obesity may be present in people with generally poor lifestyle, and that LBP occurs as a result of the combination of several slovenly habits” in such a population.

\section{Acknowledgements}

We express our tremendous gratitude to the Ministry of Higher Education Libya, for awarding scholarship to Qais. We also appreciate the effort of Sultan Zainal Abidin University for providing the necessary facilities to conduct this study.

\section{References}

[1] NICE guideline: Obesity guidance on the prevention, identification, assessment and management of overweight and obesity in adults and children (Dec 2006).

[2] Mirtz TA, Greene L. Is obesity a risk factor for low back pain? An example of using the evidence to answer a clinical question. Chiropractic \& Osteopathy 2005; 13(2): 1340-1346.

[3] Rennie K.L, Jebb S.A. 2005. Prevalence of obesity in Great Britain Obesity Reviews Volume 6, Issue 1, Date: February 2005, Pages: 11-12.

[4] Waddell G. (2004). The Back Pain Revolution, Second Edition, Churchill Livingstone.

[5] Mandiakis and Gray, 2000 N. Mandiakis and A. Gray, The economic burden of low back pain in the United Kingdom, Pain 84 (1) (2000), pp. 95-103.

[6] Wynne-Jone G, Dunn G, Main C. J. (February 2008) European Journal of Pain Volume 12, Issue 2, Pages 180-188 The impact of low back pain on work: A study in primary care consulters.

[7] Kohlmann Michel A, T, Raspe H. The association between clinical findings on physical examination and self-reported severity in back pain. Results of a population-based study. Spine 1997; 22: 296-304.

[8] Waddell G, Somerville D, Henderson I, Newton M. Objective clinical evaluation of physical impairment in chronic low back pain. Spine 1992; 17: 617-28.

[9] Power C, Frank J, Hertzman C, Schierhout G, Li L. Predictors of Low Back Pain Onset in a Prospective British Study. American Journal of Public Health 2001; 91(10): 1671-78.

[10] Leboeuf-Yde CDC. Body Weight and Low Back Pain: A Systematic Literature Review of 56 Journal Articles Reporting on 65 Epidemiologic Studies. Spine 2000; 25(2): 226-43.

[11] Aro S, Leino P. Overweight and musculoskeletal morbidity: A ten-year followup. Int J Obesity 1985; 9: 267-75.

[12] Bostman O.M., 1993, Body Mass Index and Height in patients requiring surgery for lumbar intervertebral disc herniation. Spine, 18: 851-4.

[13] Deyo RA, Bass JE. Lifestyle and low-back pain. The influence of smoking and obesity. Spine 1989; 14: 501-6.

[14] Heliövaara M. Body height, obesity, and risk of herniated lumbar intervertebral disc. Spine 1987; 12: 469-72.

[15] Kelsey J.L An epidemiological study of acute herniated lumbar intervertebral discs, Rheumatol Rehabil 1975 14:144-159. 
[16] Pope M.H., Bevins T.,Wilder D.G., Frymoyer J.W. 1985 The relationship between anthropometric, postural, muscular and mobility characteristics of males ages 18-55. Spine 10: 644-8.

[17] Wright D., Barrow S., Fisher A.D. Horsley S.D. Jayson M.I.V 1995. The influence of physical, psychological and behavioural factors on consultations for back pain. Br Jnl Rheumatol: 34: 156-61.

[18] Kostova V, Koleva M. Back disorders (low back pain, cervicobrachial and lumbosacral radicular syndromes) and some related risk factors. J Neurol Sci. 2001; 192: 17-25.

[19] Felson D.T., 1996, Weight and Osteoarthritis: AmerJnl of Clin Nutrition, 63, 430-432.

[20] Buckwalter JA, Goldberg VM, Woo SL. In: Musculoskeletal Soft Tissue Aging: Impact on Mobility. American Academy of Orthopaedic Surgeons Symposium. Rosemont, IL; 1993.

[21] Garzillo MJ, Garzillo TA. Does obesity cause low back pain? J Manipulative Physio Ther. 1994; 17: 601-4.

[22] Toda Y, Segal N, Toda T, Morimoto T, Ogawa R. Lean Body Mass and Body Fat Distribution in Participants with Chronic Low Back Pain. Arch Intern Med 2000; 160(21): 3265-3269.

[23] Ryden LA, Molgaard CA, Bobbitt S, Conway J. Occupational low-back injury in a hospital employee population: An epidemiologic analysis of multiple risk factors of a high-risk occupational group. Spine 1989; 14: 315-20.

[24] Manninen P, Riihimäki H, Heliövaara M. Incidence and risk factors of low-back pain in middle-aged farmers. Occup Med 1995; 45: 141-6.

[25] Mortimer M, Wiktorin C, Pernold G, Svensson E, Vingard E. Sports activities, body weight and smoking in relation to low-back pain: a population-based case-referent study. Scand J Med Sci Sports 2001; 11: 178-184.

[26] Bener A, Alwash R, Gaber T, Lovasz G. Obesity and Low Back Pain. Coll. Antropol. 2003; 27(1): 95-104.

[27] Leboeuf-Yde CDC, Kyvik KO, Bruun NH. Low back Pain and Lifestyle. Part 11- Obesity: Information From a Population-based sample of 29,424 Twin Subjects. Spine 1999; 24(8): 779-84.

[28] Leboeuf-Yde C. Back pain - individual and genetic factors. Journal of Electromyography and Kinesiology 2004; 14(1): 129-133.
[29] Han TS, Schouten JSAG, Lean MEJ, Seidell JC. The Prevalence of Low Back Pain and Associations with Body Fatness, Fat Distribution and Height. International J of Obesity 1997; 21: 600-7.

[30] Webb R, Brammah T, Lunt M, Urwin M, Allison T, Symmons D. Prevalence and Predictors of Intense, Chronic, and Disabling Neck and Back Pain in the UK General Population. Spine 2003; 28(11): 1195-1202.

[31] Baker PG, Giles LGF. Is Excess Weight Related to Chronic Spinal Pain? Chiropr J Aust 1999; 29: 51-4.

[32] Tsuritani I, Honda R, Noborisaka Y, Ishida M, Ishizaki M, Yamada Y. Impact of obesity on musculoskeletal pain and difficulty of daily movements in Japanese middle-aged women. The European Menopause Journal 2002; 42(1): 23-30.

[33] Sjolie AN. Low-back pain in adolescents is associated with poor hip mobility and high body mass index. Scand J Med Sci Sports 2004; 14(3): 168-175.

[34] Jones MA, Stratton G, Reilly T, Unnithan VB. Biological risk indicators for recurrent non-specific low back pain in adolescents. Br J Sports Med 2005; 39: 137-140.

[35] Fanuele JC, Abdu WA, Hanscom B, Weinstein JN. Association Between Obesity and Functional Status in Patients With Spine Disease. Spine 2002; 27(3): 306-12.

[36] Shaw K, Gennat H, O’Rourke P, Del Mar C (2007). The Cochrane Collaboration Review into Exercise for Overweight or Obesity. John Wiley and Sons, Publishers, United Kingdom.

[37] Liira, Juha P., et al. "Long-term back problems and physical work exposures in the 1990 Ontario Health Survey." American Journal of Public Health 86.3 (1996): 382-387.

[38] Smith MD, Russell A, Hodges PW. Disorders of breathing and continence have a stronger association with back pain than obesity and physical activity. Australian J of Physiotherapy 2006; 52: 11-16.

[39] Johnson, Sheena, et al. "The experience of work-related stress across occupations." Journal of managerial psychology 20.2 (2005): 178-187. 